\title{
Tenses, Aspects, and Categories of Evidentiality and Egocentricity in Spoken Lhasa Tihetan*
}

\author{
Jiang $\mathrm{Di}^{* *}$ Yue Ming ${ }^{* * *}$
}

\begin{abstract}
This paper mainly discusses verbal aspects and their syntactic markers in Lhasa Tibetan. Since aspects in Tibetan always share markers with other important categories called evidentiality and egocentricity, the former of which assesses the evidence of speaker's statement and the latter denotes behavioral characteristics of a speaker's ego-centricity, this paper simultaneously describes all three types: aspect, evidentiality and egocentricity. There are nine types of verb aspects in Lhasa Tibetan, namely: Prospective, Imminent, Premediated, Realis, Durative, Resultative, Merely-past, Perfect, and Contextual aspects. There are four types of evidentialities, namely, Self-knowledge, Knowing-by-sight, Knowing-by-newly-found-information and Knowing-by-inference evidentialities. Categories of egocentricity demonstrate whether an action is towards the Self or the Other, whether the speaker gains or loses, and so on. Additionally, this essay also discusses the interactive relationship between syntactical verb aspects and personal pronouns, intentionality, modality, as well as temporal-spatial cognition.
\end{abstract}

Key words: Lhasa dialect of Tibetan, categories of verb aspect, markers of verb aspects, evidentiality, egocentricity

\section{Introduction}

This article discusses syntactic phenomena around categories of verb aspects, evidentiality and egocentricity in the Lhasa dialect of Tibetan, focusing on verb aspects as its main subject. To make things easier, conventional names for most types of the verb aspects discussed will be used in the essay. As for the few innovated terms, or terms used

\footnotetext{
* This study is sponsored by the National Natural Science foundation of China (Number 60173024, 60473135). We thank Professors Sun Tianxin, J. L. Randy, J. A. Matisoff and Gu Yang for their constructive comments.

** Jiang Di: Humanities and Communications College, Shanghai Normal University, Shanghai 200234, China. Also: Institute of Ethnology and Anthropology, Chinese Academy of Social Sciences, Beijing 100081, China. E-mail: jiangdi@ cass.org.cn.

*** Yue Ming: School of Foreign Languages, Zhejiang University, Hangzhou 310058, Zhejiang, China. E-mail: ms.yueming@gmail.com.
} 
Tenses, Aspects, and Categories of Evidentiality and Egocentricity in Spoken Lhasa Tibetan

differently or ambiguously by scholars in earlier literature, a brief explanation will be added. Most words written in Tibetan orthographic forms have been transliterated with the IEA (Institute of Ethnology and Anthropology) mode (Jiang Di, 2006); a few were spelt in the way they are pronounced. The corpus data used in this essay comes mainly from a spoken language survey we conducted, from teaching materials in Lhasa Tibetan textbooks, and from folk arts and anecdotes. ${ }^{(1)}$

Previous studies are in wide disagreement on Tibetan "verb aspect",on whether Tibetan verbs have different aspects, or on the number of categories of aspects. For instance, JIN Peng, editor-in-chief of Zangyu Jianzhi (A Brief Introduction to Tibetan Language), proposed that Tibetan has only one perfect aspect (with all the other verb forms in non-perfect aspects), including those marked with "song", "byung", "yod", "shag" (in written Tibetan), "mi 'dug" (the above five types were considered as special declarative forms), "yog red" (considered as an extensive narrative form) (Jin, 1983:52) . Qu Aitang set 8 types of verb aspects,namely: Present, Prospective, Past, Imminent, Merely-past, Preparative, Perfect, and Resultative aspects (Qu, 2000:579) . P. Denwood (1999:140) proposed his 8 types of aspects in 3 groups, namely:

A. Perfect aspects (further divided into the Simple perfect (yod, dug yog red), Perfect with 'shag'; Conditional Subjective Perfect (yog red), Perfect with an existential verb (red 'dug / red shag)); and Recent aspect ("gro'o yin", or "grabs yin" in written form, "gro'o red", or "grabs red" in written form);

B. Progressive aspects, which P. Denwood illustrated with only one example in the pattern of "verb + mus + yin / red";

C. Prospective aspects, which is further divided into four subcategories: (a) Gerundive, with the basic form "verb+rgyu yin / rgyu red"; (b) Premeditated, with the form of "verb + mkhan yin / mkhan red", and Prospective with 'yag', which seems to be an alternative form of 'rgyu'; (c) Imminent, with the form of "verb + grabs yod / grabs 'dug / grabs yo'o red"; (d) Preparative, with the form of "verb + chog yin / chog red".

Zhou Jiwen et al. (2003: 32), however, chose to completely ignore the issue of verbal aspects by replacing them with the categories of verbal tenses. Hu Tan (2002: 77) basically agreed with Hoshi and Michio, who only distinguished the prefect from the non-perfect, and the durative from the non-durative. There are of course other minor discussions on verbal tenses and aspects scattered in other studies, to which this essay will also refer. Please see Appendix I for terms of verb tenses and aspects in Lhasa Tibetan categorized by eminent scholars.

\footnotetext{
(1) We thank the two consultants of our speech investigation, Tsebrtan-Rdorje and Migdmar-Tsering. Both of them are native Lhasa speakers.
} 


\section{Jiang Di Yue Ming}

Tibetan verbs and verb phrases involve a wide range of syntactic categories, including Person, volitionality, modality, spatial-temporal relation, reference, narrative viewpoint (ego/non-ego), speech evidence (evidentiality), and so on. The formation of these concepts is closely related to Tibetan people's life experiences and perception of the physical world. Among others, the narrative viewpoint reflected in egocentricity is a principal concept, which is linguistically represented by experiential classification of grammatical functional markers, as well as predicate verbs. Owing to the diversity of the experiential world, the classification is indeed a complicated interaction of categories. For instance, subjective volitionality can be dependent or independent; egocentric perception can be either an extrovert or introvert referential behavior; first-hand experience can be determinant or non-determinant; events can be of various progressive states under self-observation: just started or already finished, durative or realized; or of various evidential properties based on the evidences produced during the speech. All these notions are represented more or less through various syntactic forms of verbs or verb phrases (though some forms carry certain semantic meanings), and some have even been grammaticalized. Verbal aspects, evidentiality and their syntactic formal markers discussed in this essay reflect the linguistic representation of the Tibetan people's view of the world.

This essay holds that there are basically nine types of "verbal aspect" in Tibetan, namely: the Prospective aspect, Imminent aspect, Premediated aspect, Realis, the Durative aspect, Resultative aspect, Merely-past aspect, Perfect aspect, and the Contextual aspect. All these syntactic aspects have their own formal markers. On the other hand, Tibetan categories of aspects always share their formal markers with evidentiality and egocentricity. Hence this paper will also describe evidentiality types which evaluate the speaker's evidence and egocentricity types which reflect the speaker's egocentric behavior. ${ }^{(2)}$

\section{Prospective aspect}

The Prospective aspect in Lhasa dialect may also be called the Premeditated aspect. It indicates a premeditated action (or event) closing-up to the scheduled time of its happening. This is of course quite subjective. The Pprospective aspect takes 'gi yin' and 'gi red' as its

\footnotetext{
(2) This essay uses the following signs: $\mathrm{C}=$ connective;m.w=mood word;tap=target particle;cop=complement particle;cau=causative particle;pap=pause particle;hop=honorific particle;stc $=$ state

complement;agn=agentive;pos=possessive;loc=locative; dat=dative;obj=objective; ala=allative $;$ gen=genitiv e;ins=instrumental;abl=ablative;pro=prospective aspect;imm=imminent aspect;prm=premeditated aspect;rea=realis;dur=durative aspect;mer=merely past aspect;rst=resultative;con=contextual;pef=perfect aspect;eg=self-knowing (ego);sf=knowing-by-sight;ni=knowing-by-newly-found-information;jd=knowing by inferential;nom=nominization. Please refer to the Appendices at the end this paper. For more details, see Jiang Di,2004.
} 
Tenses, Aspects, and Categories of Evidentiality and Egocentricity in Spoken Lhasa Tibetan

formal markers, the former suggesting the narrator's desire to show his/her confidence and grounds, and the latter suggesting the narrator's estimation or speculation about other people's behavior according to his/her experiences. From this pragmatic perspective, there is some evidentiality differences between "gi yin" and "gi red", with the former being a formal marker of self-conscious evidentiality in the prospective aspect (pro.eg) and the latter a formal marker of extrapolated evidentiality (pro.jd) (also see Appendix II) .

(1) nga dang pha-yul-gyi yul-mi-tsho-s khyed-rang-la dga'-bsu-zhu gi-yin.

I C hometown-GEN folks-AG you-OBJ welcome-PRO.EG

Folks and I welcome you.

(2) sang-nyin slob-grogs-tsho po-lo rgyag- gi-red.

Tomorrow schoolmates ball play-PRO.JD

Schoolmates are to play a ball game tomorrow.

According to the Tibetan syntactic rules, the subject of a sentence in prospective aspect usually has an agentive tag, but in Lhasa dialect these markers are not compulsory. Agentive tags are added only when special emphasis is needed or when there is the possibility of misunderstanding the sentence.

(3) khyed-rang-kyi bka'-drin de nga-s brjed-kyi-ma-red.

You-GEN kindness that I-AG forget-NEG-PRO

I will never forget your kindness.

The Prospective aspect in Tibetan entails some presupposition to the state of the occurrence of an event. If such occurrence becomes a convention or inevitable consequence, then new syntactic signification can be derived, including a relationship of cause-and-effect speculation, and lasting status of the occurrence of the event.

(4) gza'-shag-pa-'i dgong-dga chu-tshod bzhi-pa-r spir-btang-byas-na glog-brnyan bstan-gyi-red

Wednesday-GEN afternoon o'clock four-LOC usually movie show-PRO

Usually there will be a movie at 4 o'clock on Wednesday afternoon.

(5) nyi-ma shar-phyogs-nas shar-gyi-red. nub-phyogs-la nub-kyi-red.

Sun east-ABL rise-PROSE west-ABL set-PRO

The Sun rises in the East and sets in the West.

While "gi yin" is usually used after volitional verbs, "gi red" can be used after both volitional and non-volitional verbs due to its representation of habitual actions or inevitable physical phenomena.

(6) mi-gcig-la cha-bzhag-na sems-chung-byas na yar-rgyas-' gro-gi-red.

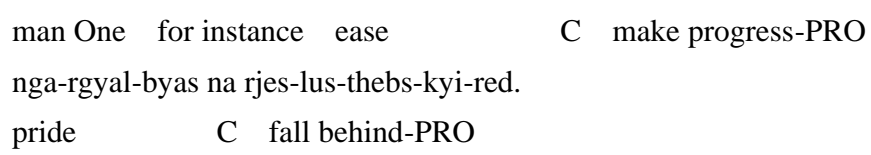

Take humans as an example, modesty helps one go forward, whereas conceit makes one lag 


\section{Jiang Di Yue Ming}

behind.

(7) sman tog-tsam bzas na tsha-ba de mar-bcag thub kyi-red.

Medicine a little take $\mathrm{C}$ pain the relieve can-PRO

Take some pills, and the pain shall be relieved.

The prospective aspect marker "gi red" can also be used after adjectival predicates for comparison.

(8) bkra-shis-las don-grub gzugs-po ring-gi-red.

Bkra-shis-las-COC don-grub body-height tall-PRO

Don-grub is taller than bkra-shis.

As to the syntactic function of "verb+gi yin /gi red" pattern in Lhasa Tibetan, C. A. Bell (1905:47),Jin Peng (1983:45), Zhou Jiwen (2003:98), and P. Denwood (1999:155) all regarded it as a marker of tense, while Qu Aitang and Tan Kerang (1983) regarded it as a marker of the prospective aspect. We agree with Qu and Tan.

In addition, "gi yin" has a function similar to that of "gi red" in marking the status of prospective events, yet the meaning of habitual actions and inevitability that "gi red" has evolved into has no match in "gi yin". This is because the meaning of habit or inevitability is an opposite notion to the speaker's volitionality. Consequently, "verb + gi red" as a form of inevitability may also be excluded from the prospective aspect to form a category of customary aspect, which will be discussed in another essay.

The verbal ending "mkhan yin / mkhan red" can also be used in the prospective aspect in Lhasa dialect. "yin / red" was originally a lexical suffix attached to verbs to indicate the agent, while "yin/red" was originally a copular verb. The marker may have been grammaticalized from this type of combined copular sentences.

(9) khyed-rang ga-par thad-mkhan-yin-pa.

You where go-PRO-M.W

Where are you going.

(10) khyed-rang phir-ju'u nyo-ka thad-mkhan-red 'dug ga.

You beer buy-TAP go-PRO-M.W

Are you going to buy some beer.

\section{Imminent aspect}

There are three formal markers, "grabs yod", "grabs 'dug", and "grabs yo'o red" for the Imminent aspect. "grabs" in Lhasa dialect is pronunced as [tşo $\left.{ }^{55}\right]$, or "gro'o" or "'gro'o" in writing. The Imminent aspect means an action is about to happen. It does not usually imply premediation as the prospective aspect does.

(11) gnam 'thibs-shag. char-pa 'bab-grabs-'dug.

sky overcast-RST rain fall-IMM 
Tenses, Aspects, and Categories of Evidentiality and Egocentricity in Spoken Lhasa Tibetan

It's getting dark. It's about to rain.

(12) a-cag-lags. stag-rtse-rdzong-la slebs-grabs-yo'o-red-pas.

Sister(Hon) Stag-rtse-county-LOC arrive-IMM-M.W

Sister, are we about to arrive at stag-rtse county?

(13) shing-bzo-bas sna-ru-'i khebs gcig bzos byas.

Carpenter ox horn-GEN cover one made-C

nyi-ma nub-grabs-yod-dus phyug-bdag-kho-la sprad.

sun sunset-IMM NOM landlord-DAT give

The carpenter made a horn cap, and gave it to the landlord when the sun was about to set.

Jin Peng (1983:46) regarded "grabs yod","grabs 'dug",and "grabs yo'o red" as markers of an Imminent Tense, with the first two markers differentiating from the last marker in mood (special declarative mood vs. general declarative mood), and the difference between the first two lies in the narrator's evidentiality, that is, a difference of whether the narrator has knowing-by-sight affirmation or can only make a subjective judgment. Yet future events are anyhow different from those events happened, and therefore always bear a color of being speculated, no matter how strong the evidentiality is. Sentence (11) with "grabs vdug" is a speculation based on some experiences, while sentence (13) with "grabs yod" has much certainty (that schools usually start at 8 o'clock in the morning). Generally speaking, there are many deep-rooted factors that influence the selection of aspectual markers in Tibetan speech, including the speaker's volitionality and degree of concern, the time and place of the event occurred, the relation between the speaker and the event, and so on.

(14) da chu-tshod-bdun dang skar-ma lnga-bcu slebs-shag. dge-rgan yong-grabs-yod.

Now seven o'clock $\mathrm{C}$ fifty minutes arrive to-RST teacher come-IMM

It's seven fifty already. The teacher is coming.

The difference between volitional and non-volitional verbs in sentences of imminent aspect also suggests certain objectivity of the event occurrence. In regard to volitional verbs, the speaker represented by self-reference may be volitional, but may also entail other factors such as responsibility, obligation, convention, etc. For instance,

(15) da-dus-chod slebs-grabs-' dug. nga kha-la bzo-grabs-yod.

Time arrive-IMM I meal cook-IMM

It's time for me to cook the meal.

(16) zhi-mi 'dis nya zin-grabs-'dug.

Cat this fish catch-IMM

The cat is about to catch some fish.

On the contrary, non-volitional verbs usually indicate a stronger objectivity. For instance,

(17) khong-gi ming nga-s brjed-grabs-' dug. 


\section{Jiang Di Yue Ming}

\section{His-GEN name I-AG forget-IMM}

I have almost forgot his name.

The multiple markers of the Imminent aspect entail many meanings, as the occurrence and existence of multiple forms must be driven by multiple functions. At least three hierarchies can be distinguished from the interrelationship between those functions and markers. In Table 1, the deepest concept is narrative viewpoint, which is related to human cognitive experiences in early enclosed societies and is recorded in language. The narrative concept has a cultural heritage principally embodied in "egoness" and "nonegoness". "Egoness", is an "ego-centric point of view" which takes the real world as a context around the speaker; whereas "non-egoness" indicates a "non-egocentric" or "other-centric" viewpoint (see also the discussion on "Perfect apsect"). The Evidentiality layer, however, reflects how the speaker observes the world and how he categorizes his evaluation of events, for Tibetan people believe that speech evidentiality must be overtly expressed in the discourse. Such parameters entail content semantic and logical conditionality, among which Person and verb volitionality not only interact with other syntactic elements in the discourse, but also relate to discursive viewpoint and experiential knowledge. Furthermore, self-reference means using a first-person pronoun, while other-reference includes second-person and third person pronouns. The benefit of using such a classification of Person was discussed in detail by Sun Tianxin (1995) from a pragmatic conversational principle and evidentiality perspective. This paper also adopts this classification.

Of course there will be some exceptional cases, such as those pointed out by Zhou Jiwen (2003:106): "grabs yo'o red" can be used to mean "the elapsed future", for instance, "chu tshod drug par (six o'clock) slebs (arrive) shag. khong (he) slob grwa'i nang la (at school) sdod (stay) dus (time). da (now) lang (get up) grabs yo'o red." (It's six o'clock. He would have got up when he was at the boarding school.). The notion of time is included here. And last but not least, the time of the event occurrence will absolutely be influenced by the person's experiential knowledge. Because the evidentiality of future events is mainly based on previous experiences, and life experiences differ from person to person, case to case, there will be some free variations in the evidentiality layer, which will consequently lead to some chaos in the selection of narrative viewpoint, and finally to the collocation and marking of the parameters. These phenomena may also interact with the development of the language. 
Tenses, Aspects, and Categories of Evidentiality and Egocentricity in Spoken Lhasa Tibetan

Table 1 Imminent aspect markers and constraint parameters in the Lhasa dialect

\begin{tabular}{|c|c|c|c|c|}
\hline $\begin{array}{l}\text { Narrative } \\
\text { Viewpoint }\end{array}$ & Ego & \multicolumn{3}{|c|}{ Non-ego } \\
\hline Evidential Type & Meta-evidence & \multicolumn{2}{|c|}{ Direct Evidence } & Indirect Evidence \\
\hline \multirow{2}{*}{$\begin{array}{l}\text { Experiential } \\
\text { Knowledge } \\
\text { Explanation }\end{array}$} & $\begin{array}{l}\text { self-knowledge } \\
\text { (personal } \\
\text { experience) }\end{array}$ & $\begin{array}{l}\text { knowing-by- } \\
\text { sight (speculation } \\
\text { personal witness) }\end{array}$ & $\begin{array}{l}\text { knowing-by-newly- } \\
\text { found-information } \\
\text { (discover) }\end{array}$ & $\begin{array}{l}\text { knowing-by- } \\
\text { inferential } \\
\text { (speculation) }\end{array}$ \\
\hline & I did ... & (I saw) he did... & $\begin{array}{c}\text { (I realize that I was) } \\
\text { done by... }\end{array}$ & $\begin{array}{l}\text { (I guess) he was... } \\
\text { / I was done by... }\end{array}$ \\
\hline $\begin{array}{c}\text { Parameter } \\
\text { Relationship }\end{array}$ & $\begin{array}{c}\text { self-reference, } \\
\text { [+volitional }]\end{array}$ & $\begin{array}{l}\text { referring to the } \\
\text { other, } \\
\text { [ } \pm \text { volitional }]\end{array}$ & $\begin{array}{c}\text { self-reference, } \\
\text { [-volitional] }\end{array}$ & $\begin{array}{c}\text { self-reference, } \\
{[\text {-volitional] / }} \\
\text { referring to the } \\
\text { other, }[ \pm \text { volitional }]\end{array}$ \\
\hline Formal Marker & grabs yod & grabs & vdug & grabs yovo red \\
\hline
\end{tabular}

Apart from those imminent aspect markers discussed above, there is another expression in Lhasa Tibetan to express the occurrence of events, that is, "Verb + grabs byed kyis". The verb in this pattern can be reduplicated, as in:

(18) de-dus shar-phyogs-nas nyi-ma dmar-chem-chem shar-grabs-shar-grabs-byed-kyis.

$$
\text { Then orient-ABL sun red rise(-IMM)-DUR }
$$

The red sun was about to rise from the East.

However, it may not be proper to regard this expression as a syntactic aspectual marker in Tibetan.

\section{Premediated aspect}

This aspect is unique in that it has a dual meaning: the event is about to happen but has not yet happened. In other words, it entails the inevitability of the occurrence of the event, while denying the happening of the event. Consequently, this dual meaning is represented as syntactically-semantically known. The Premeditated aspect suggests some objectivity of the occurrence of an event, such as the occurrence of objective needs, customs, regulations, etc.

Verbs in the Premediated aspect are added with "rgyu yin" or "rgyu red", depending on whether the speaker makes his own decision or he speculates on other's behavior. As analyzed above, when the speaker volitionally decides his own actions, pragmatically it's an egocentric behavior, and this egocentric viewpoint takes the marker "rgyu yin", rather than the non-egocentric "rgyu red", the non-volitional self-reference pattern included. For instance, sentence (20) implies the meaning that "they asked us to help the chef".

(19) nga bod-pa-vi a-ce-lha-mo lta-rgyu-yin.

I Tibetan-GEN drama saw-PRM

I have never seen a Tibetan drama. (I'm going to see one right now.)

(20) nga-tsho-s las-ka ga-re byed-rgyu-red. 


\title{
Jiang Di Yue Ming
}

\author{
We-AG task what do-PRM \\ de-ring nga-tsho ma-chen-gyi rogs-pa-byed-rgyu-red. \\ today we chef-GEN help-PRM. \\ What are we going to do? We are to help the chef.
}

Sentences in premediated aspect cannot be in the negative form, for the aspect indicates the event is yet to happen.

(21) nga sbi-rag shil-dam pha-gi btung-tshar-rgyu-yin.

I beer bottle the drunk-STC-PRM

I have not yet drunk that bottle of beer.

(22) bgra-shis kha-lag za-rgyu-red-pas.

bkra-shis meal eat-PRM-M.W

Has bkra-shis not yet had his meal?

"rgyu + rang (adv., meaning 'very, completely') + red" is a sentence pattern in the Lhasa dialect that can also indicate the premediated aspect of an event. For instance,

(23) am-chi yag-po 'di-' dras-med na nga shi-rgyu-rang-red.

doctor good in this way-NEG C I die-M.W

Had I not seen such a good doctor, I would certainly have died.

Scholars are divided on the categorization of this structure. Zhou Jiwen (2003:108) considered it to be a marker of the future tense, while P. Denwood (1999:233) regarded "rgyu" as a marker of nominalization. We agree with Denwood,and exclude "rgyu rang red" from the markers for the Premediated aspect.

\section{Durative aspect}

The Durative aspect in Lhasa Tibetan is used to refer to ongoing actions or actions that are repeated during a certain period of time. Durative events, durative states, and customary conventions are also included.

"verb+ gi yod / gi 'dug / gi yo'o red" are formal markers for the Durative aspect. "gi yod" is usually used to indicate the self-reference of the speaker's volition, or the closeness or relatedness to the speaker's volition, while "gi 'dug" and "gi yo'o red" are used in cases of other-reference.

Most action verbs clearly indicate an ongoing state of an event, suggesting that the action is still in a durative progress.

(24) nga-s skyid-pa-'i pha-yul yar-klung-la glu gzhig 'bul-gyi-yod.

I-AG happy-GEN hometown yar-klung-la-OBJ song one deliver-DUR

I'm singing a song for my happy hometown Yar-klung.

(25) sgrol-ma-lags. Khyed-rang ya'i snyun-gyi-' dug gas.

Sgrol-ma-HOP you too become sick-DUR-M.W 
Tenses, Aspects, and Categories of Evidentiality and Egocentricity in Spoken Lhasa Tibetan

Sgrol-ma, are you feeling sick, too?

(26) bu-mo-snang-sa-s mi-mang-po-'i dkyil-nas gar-'cham-la ltad gi-yo' o-red.

girl snag-sa-AG crowd-GEN middle-ABL Itad-OBJ see-DUR

Snag-sa is in the crowd watching Itad.

Suggesting the ongoingness of an event, the Durative aspect does not entail any ending point. Hence, many general statements, or philosophical/scientific statements, and proverbs such as "the Earth moves round the Sun" in English, are all of this feature. Some static verbs and weak action verbs have a similar feature, with but a limited time span, like in "She knows several languages". Therefore, the Durative aspect indicates not only the progress, but also the status of an event, a custom, and certain ability in a given period of time. It indicates the durativity of an event, but not the temporal past, present or future.

(27) nga-tsho tshang-ma-s mes-rgyul-la dga'-zhen-byed-kyi-yod.

We all-AG fatherland-OBJ love-DUR

All of us love our fatherland.

(28) dbyar-kha tsha-gtug-tshig-gi-' dug-gas.

Summer hot-DUR-M.W

Is the summer hot?

(29) tshwar-' dam sa-khul-la tshwa 'bel-po yod tsang. Ma-btaon na'i don-gyi-yo'o-red.

Tshwar-'dam region-LOC salt exuberance have so not take C outflow-DUR

Salt is abundant in the Tshwar-' dam region, it comes out itself without any labour effort.

The convention of an event or action repeating itself regularly (every day/week/year/etc.) is a state of the event in that given period. A fixed lifestyle, or an equivalent exchange, is a state as well.

(30) lha-mo nyin-ltar po-lo rgyag-gi-yo'o-red.

Lha-mo everyday ballgame play-DUR.JD

Lha-mo plays ball every day.

(31) sha-khog gcig-la rcam-pa rgya-ma-brgya-re brje-gi-yod .

Mutton one-body-POS tsam ba hundred jin exchange-DUR

One body of mutton barters for fifty kilos of tsamba. (by the Seller)

(32) bod-la 'bras dang ma-rmos-lo-tog ci-dag skye-gi-a-yod.

Tibet-LOC rice $\mathrm{C}$ maize etc. grow-DUR

Do rice, maize and so on grow in Tibet?

Markers of the durative aspect may be put after an auxiliary verb of volitional ability. Without an auxiliary verb, however, the sentence may also represent some volitionality.

(33) rang-gis 'khyog thub-kyi-' dug.

You-AG raise can-DUR

Can you lift and carry this? 


\section{Jiang Di Yue Ming}

(34) blo-bzang-lags snyun tsang. 'dzin-grwa-tshogs gag phebs thub-kyi-mi-'dug. blo-bzang sick consequently attend class TAP come can-NEG-DUR blo-bzang is sick. So he's not able to come to class.

Distribution of these three markers of the Durative aspect is fairly distinctive, and to some extent, related to the context in some exceptional cases. Take sentence (31) for instance, "V+gi yod" is an expression used by the seller. A buyer will usually use "V+gi vdug". Besides, an interrogative expression may also bring some relational variation.

(35) khos 'di ni rang-la yig-tshad-btang-gi-yo'o-red. Lon thub-kyi-red. Brel-ba-ma-byed

$\mathrm{He}$ that you-OBJ test-DUR

pass can-PRO

anxious-NEG

Don't be anxious. He's just testing you. You can pass it.

(36) khyed-tsho bod-kyi lo-rgyus slob-sbyong-gnang-gi-yod-pas.

You-Pl. Tibetan-GEN history study-DUR-M.W

Are you studying Tibetan history?

\section{Merely-past aspect}

The Merely-past aspect refers to the state when an action has just happened, or when an event has just finished. It is usually marked with "gro'o yin" or "gro'o red" in Lhasa Tibetan. The Merely-past aspect can be represented in writing by "gro'o yin" and "gro'o red", as well as by "grabs yin" and "grabs red". In written Tibetan, "grabs" by itself means "near upon, drawn on" (adverb), or "preparation, prepare" (noun). So it is quite understandable for it to assume such a grammaticalized meaning when attached to a verb in the present tense. Besides, it is logically proper for "grabs" in the imminent aspect to be attached to the future tense of a verb. In addition, there is no negation in the merely past aspect--its negation in the sense of lasting time is expressed by the perfect aspect.

(37) nga gzugs-po-bkrus-tshar-grabs-yin. Tog tsam song nas kho-la kha-par-brgyab-kyi-yin.

I bathe-STC-MER a moment later him-DAT phone back-PRO

I've just finished bathing. I will phone him in a minute.

(38) da-lta tshogs-' dra grol-grabs-red. khong-tsho 'gro-grabs-red.

Now conference dismiss-MER they go-MER

The meeting is over, they've just gone.

Choice over the two markers of the Merely-past aspect can be made by whether there is an egocentric or non-egocentric narrative viewpoint. In most cases, the first-person pronoun refers to the narrator, but in some others (such as in performative sentences) the narrator can be inexplicit or omitted.

(39) nga gnam-gru babs-grabs-yin. Ngal-gso tog-tsam brgyab dgos-kyi-red-par.

I plane take off-MER take a rest V need-PRO-M.W

I just got off the plane, and therefore need some rest. 
Tenses, Aspects, and Categories of Evidentiality and Egocentricity in Spoken Lhasa Tibetan

(40) kho-tsho ri nas babs-grabs-red. Rang mgyogs-tsam-byas na rjes-zin-gyi-red.

They mountain-ABL get down-MER you quickly $\quad \mathrm{C}$ catch up-PRO

They've just gone down the mountain. You may catch up if you speed up.

A sentence of the Merely-past aspect may have a volitional or non-volitional verb. However its subject takes no agentive marker even if it is a volitional verb sentence. Zhou Jiwen (2003:121) considered this to be a copular predicate structure, which needs no subject in the agentive case. This essay holds, however,that syntactically it is better to regarded "grab" as a marker of aspect.

(41) kho slob-grwar-'gro-gi-ma-red. Kho na-grabs-red.

$\mathrm{He}$ go to school-NEG-PRO he be ill-MER

He's not going to school. He's sick.

(42) nga dpe-cha lta-grabs-yin.

I book read-MER

I have been reading a book.

The following two sentences taken from Jin Peng (1983:51) have different markers for the self-reference and the other-reference. They entail a different semantic meaning of "almost done". We are not to disscuss such phenomenon since there's no such case in our corpus.

(43) nga-s sman nor-byas za-grabs-red.

I-AG medicine wrongly eat-MER

I almost took the wrong medication.

(44) khong dug-log 'khru grabs-yin.

$\mathrm{He}$ dress wash-MER

He almost washed the dress. (It shouldn't be washed.)

Both Zhou Jiwen (2003:122) and P. Denwood (1999:161) said that "verb+pa da ga + yin/red" can also mean "the action has just finished ". But Zhou took the first as in a sentence with a copular verb, while Denwood took it as an action of the perfect aspect.

(45) khong slebs-pa-da-ga-ma-red.

He arrive-NEG-MER

He is not just arrived. (Zhou)

(46) nga-s kha-la bzos-pa-da-ga-yin.

I-AG meal cook-MER

I have just cooked a meal. (Denwood)

"pa da ga" is a common word in the Lhasa dialect principally functioning as a conjunction or an adverb. Its alternative spelling in spoken form is "pa dang" (M. C. Goldstein, 1978:668). Syntactically speaking, it is quite proper to this formal as a Merely-past aspect. 


\section{Jiang Di Yue Ming}

\section{Realis}

The Realis aspect in Lhasa Tibetan is marked by "pa yin" or "pa red", with a preceding verb in the form of past tense usually illustrated in traditional grammar books. "Realis" means the action the verb denotes has either occurred, finished, or been realized. Hoshi, Michio (in Hu Tan, 2002), who said the Lhasa dialect has only two aspects, namely the perfect aspect and the imperfective aspect, considered "pa yin/pa red" and "song/byung" as markers of the Perfect-nondurative aspect. Jin Peng (1983: 52), however, took "pa yin/pa red" as markers of a tense (the Past tense) and "song/byung" as markers of the Perfect aspect. Qu Aitang et al. (1983: 80) considered "pa yin/pa red" to be markers of the Perfect aspect. Obviously, there are quite some differences not only in the terms but also in the concepts employed. ${ }^{3}$

First of all, the notion of Realis has nothing to do with the notion of tense, for, as illustrated below, the aspectual marker "pa yin/pa red" can be added to all the verbs in the following sentences, regardless of whether the action (or event) is in the past, or at the present, or even in the future.

(47) nga slob-grwar ma-yong gong-la bod-la las-ka lo-gsum byas-pa-yin.

I school not come before Tibet-LOC work three years do-REA

I had worked in Tibet for three years before coming to school.

(48) mi-dmangs-kyi 'tsho-ba yag-ru phyin-pa-red.

People-GEN life good-COP change-REA

People's life has been improved.

Example 47 is a statement of some past event or action, and therefore is in the past. Sentence 48, however, is a statement of some present events.

Secondly, Realis and Perfective are two different notions. "Realis" is about whether the action has been a fact; "Perfective" is about whether the action is finished. (Liu Xunning, 1988). Sentence 49 below is not concerned about whether the action of running away is completed or not, nor is there a notion of the end of being lost. All it tells is the reality that the children have got lost.
(49) bros-pa-'i
lam-kha-r sbu gu 'di gnyis lam-nor-thebs-pa-red.

Flee-NOM-GEN on the way-LOC children these two get lost-REA

The two children got lost while they were fleeing.

The two markers of the Realis aspect indicate two different sources of information, one with the speaker's self-knowledge, the other with inferred knowledge. Self-knowledge

\footnotetext{
${ }^{3}$ In western linguistic literature, perfective- imperfective and realis-irrealis are syntactic categories of verbal aspect and modality respectively. This essay takes "pa yin /pa red" in Lhasa Tibetan as a syntactic marker of verbal aspect. I thank J. L. Randy for bringing up the topic of realis, which urged me to read and learn more about the issue in other languages and make a compartive study on realis.
} 
Tenses, Aspects, and Categories of Evidentiality and Egocentricity in Spoken Lhasa Tibetan

means the speaker is describing an event with his first-hand experience, and therefore with a subjective certainty; inferred knowledge means the speaker is speaking with his empirical deduction or is quoting from another information source. Further analyses show that the narrator's perspective is another important factor in the selection of Realis markers. Self-reference should be used to keep the agreement with the Ego, when the speaker speaks from his personal view (or an ego-centric perspective). With this provision, the narrator describes his first-hand experience with a first-person pronoun to express such a perspective. There is no need for any special marker of evidentiality. Non-egocentric actions, however, need some special formal marker to indicate the source of the speech.

Negative sentences in Realis are a bit different. Since the ending "pa yin /pa red" indicates the occurrence and realization of an action/event which can be either positive or negative, the negation of the realization of an event can only be achieved through the negation of the event. That is to say, the negative form of sentences in Realis must be expressed through the negation of the event. Consequently, the occurrence of an action or the emergence of an event can no longer be expressed with endings of Realis. Compare the following two sentences.

(50) nga-s khyed-rang-la ku-re-ma-byas.

I-AG you-OBJ joke-NEG-REA

I'm not kidding you.

(51) nga-s khyed-rang-la ku-re-byas-pa-yin.

I-AG you-OBJ joke-REA

I'm kidding you.

When a sentence has a Realis ending while negating an action or event, it usually entails some special meaning. As far as sentences with volitional verbs are concerned, this usually indicates a strong subjective opinion, meaning "the action has not been realized, though it could have been realized".

(52) khyed-tsho-'i 'dzin-grwa-'i mi ma-ldang-pa-yin na

You-GEN class-GEN people NEG-enough-REA C

nga-tsho-s mi btang dgos-byung na btang chog.

we-AG people send need $\mathrm{C}$ send can

If your class did not have enough people, we could have sent some had you needed.

(Subjunctive Mood)

(53) sgrol-dkar-lags kha'i-sa 'dir ma-phebs-pa-red.

Sgrol-dkar-Hop here NEG-come-REA

Sgrol-dkar-lags has not come. (Either he deliberately chose not to come, or he failed to keep his promise to come.)

As to non-volitional actions or events, whether they will occur or not is constrained by objective conditions. Since extraneous factor(s) can only be satisfied through the negation 


\section{Jiang Di Yue Ming}

of an event, it usually entails some semantic emphasis on the objective cause.

(54) de-nas rgyal-yongs-kyi blon-'bangs-tshos ga-sa-ga-la shing-gi lo-ma

And then whole country-GEN subjects-AG everywhere tree-GEN leaves

de-'tshal-gag Phyin byas rkang-pa na-na-rgyugs na'i ma-rnyed-pa-red.

that look for-TAP Go leg run break C NEG-find-REA

Then the subjects looked for such foliage over all the country. They couldn't find it even when their legs were hurt.

(55) a-khu-khro-thung-gis lta-sras lkog gsod-gtong rgyu-'i re-ngan tshang-ma ma-grwab-pa-red.

Uncle khro-thung-AG prince assassination-NOM-GEN conspire all NEG-succeed-REA

Uncle khro-thung hasn't succeeded in assassinating the prince.

The negation of Realis sentences ended with "pa red" is quite unique in that it is expressed through the direct negation of the existence of the event, with an "yog ma red" ending attached to the verb to mean the non-existence of the action. "yog ma red" is a grammatized negative form of an existential verb.

(56) khyed-rang da-lta bod-zas gzhan-dga mchod-yo'o-ma-red-pa.

You now Tibetan food other taste-NEG-REA-M.W

Oh, you haven't tasted other Tibetan foods yet, have you?

(57) yin-na'i yi-ge klog-mkhan de-s de-'dras-zer klog-yo'o-ma-red.

Consequently word read-NOM that-AG in this way read-NEG-REA

None the less, people don't read it this way.

\section{Perfect aspect}

Predicate verb markers of "song" and "byung" in Lhasa Tibetan are widely regarded as formal markers of the Perfect (aspect / tense), for example by C. A. Bell (1905:46), H. B.Hannah (1912:276), C. B. Shefts \& Kun Chang (1981:303-321), Jin Peng (1983:52), Qu Aitang et al. (1983:82), and Hu Tan (2002). We think, however, that "verb in past tense+song/byung" indicates not just the occurrence of an action or the change of a state by the time of the speech, it also indicates the speaker's observance of the change or new situation. None the less,the speaker's emphasis is not on the completion but on the occurrence of the action. So we put it in the category of Perfect Aspect.

There are two formal markers of the Perfect apsect in Lhasa Tibetan, "byung" and "song" (4) Their distributions are commonly considered to be restricted by Person and

\footnotetext{
(4) We will come to the issue of egocentricity of sentences with "song/byung". Here is just a brief illustration of the Perfect aspect using the "Ego" theory in Sociology. According to the sociologist G. H. Mead, there are two kinds of "self": the "subjective self" and the "objective self". The "subjective self" is revealed from experiences and is of the past; the "objective self" is happening and of the moment. The narrator's egocentric narration, therefore, is of events already happened in the past.
} 
Tenses, Aspects, and Categories of Evidentiality and Egocentricity in Spoken Lhasa Tibetan

volitionality. Among the four combination patterns of pronoun and volitional verb, "song" can be used in three, and "byung" in two. Neither "song" nor "byung" appear in the "self-person volitional" verb pattern.

Other-person volitional verb sentence:

(58) rgan-lags-kyis bu-mo chung-chung 'di-r sgrung gcig gsung song.

Teacher-AG girl young this-DAT tale one tell-PEF

The teacher told the young girl a story.

(59) nga chung dus-nas spo-bo-lags-kyi rta-'i lo rgan-gzhun btsi-stangs tshang-ma bslabs-byung.

I childhood-ABL granddad-GEN horse-GEN age calculation method all study-PEF

Granddad taught me how to assess the age of a horse when I was young.

Other-person non-volitional verb sentence:

(60) kho glo-brgyab-nas zla-ba gcig phyin-tshar-song.

$\mathrm{He}$ cough month one keep-STC-PEF

Yin-na'i na-tsha drags-ru 'gro-yas mi-'dug.

but disease recover-COP change-NOM NEG-have

He has been coughing for one month now. There is still no sign of relief.

Self-person non-volitional verb sentence:

(61) khyed-rang de-' dra-'i mkhyen-pa-yangs-pa la

You such-GEN learnedness

nga slob-grwa-chen-mo-ba khyed-rang-la hang-sang-song.

I colleg graduate you-OBJ surprise-PEF

As a college graduate I am surprised to know that you are such a knowledgable man.

(62) bu-mo 'di-'i ming nga dran-byung.

Girl this-GEN name I recall-PEF

Now I remember the girl's name.

It is quite reasonable that "song" and "byung" don't appear in self-person volitional verb sentences. Firstly, sentences of this type indicate the speaker's recent discovery of the occurrence of a stated action. "Discovery" means that the speaker was not personally involved in the event--he only got the information from personal observation--and any person involved in the event could only be referred to through a other-person pronoun. So this is knowing-by-sight evidentiality. On the other hand, if the speaker was involved in the event, then it was a non-volitional action of him (knowing-by-newly-found-information evidentiality). Secondly, there is a notion of distance-to-event-occurrence in the Tibetan aspect system, such as the contrast between the prospective aspect and imminent aspect (along with other differences), and the contrast between the perfect aspect and the merely-past aspect. The Realis aspect is used in Tibetan for events which happened earlier, taking up the "self-reference+volitional" combination. Nonetheless, the Perfect aspect may 


\section{Jiang Di Yue Ming}

also suggest to a certain extent the occurrence of an event or the realization of an action. This was exactly the reason that scholars such as Denwood et al. considered "pa yin/pa red", "song/byung" to be formal markers of one single category. In fact, there are some differences in terms of the narrative point of view.

The most outstanding feature of "song" and "byung" as markers for the Perfect aspect is that they entail a concept different from other concepts of aspect. The difference does not lie primarily in the pronoun used, or in the volitionality of the verb, nor in the temporal distance, nor in evidentiality. Let's look at some sentences first.

(63) nga na dus blo-mthun-tsho-s blta-gag thengs ma-rdzag-to phebs-byung.

I sick when comrades-AG see-TAP times many come-PEF

Comrades came to see me many times when I was sick.

(64) de-ring khang-pa gsar-pa-r spos pa-da-gar khyed-rang phebs-byung.

Today house new-ALA move once... You come-PEF

We are just moving into the new house today when you come.

(65) nga-'i nang-la sdod-mkhan 'grul-pa-tsho phyin-da-phyin-tshar-song.

I-GEN home-LOC stay-NOM guest gone-STC-PEF

yin-na'i da-dung ca-lag mang-po bcol-byung.

but still things many leave-PEF

Although our guests have gone, they still left many of their belongs in our house.

These sentences with "byung" are all sentences of the self-person volitional verb pattern. A common feature is that all verbs direct to the speaker's cognitive center. A more detailed study will find that there are several types of cognitive centers: (a) the Ego of the speaker as center, as in sentence (63); (b) the location or position of the speaker as center, as in sentence (64); (c) the people/things that the speaker identifies with as the center, as in (65).

If a sentence is self-referent, it usually reveals what the speaker has personally sensed or noticed. In such circumstances, several different types of verbs are commonly found: "see, hear, know, understand, meet, feel sick, feel hungry, arrive" as uncontrollable actions; "get, remember, win, discover, dream, obtain" as unintentional actions. All of them are semantically self-referent, syntactically non-volitional, and result in either some new information related to the speaker, or something the speaker gets. i.e., the speaker is the center of the consequence of the action or the direction of the action. For instance:

(66) kho nag-chu'u slebs-' dug. Nga-s kho mgron-bsu-khang-la 'dzul-pa mthong-byung.

$\mathrm{He}$ nag-chu'u come-RST I-AG he hostel-ALA entering-NOM see-PEF

He's in Nag-chu'u(county name) now. I saw him entering the hostel.

(67) nga-'i lcags-smyug nag-po de brlag-shag. Ga-sa-ga-la 'tshal na'i rnyed-ma-byung.

I-GEN pen black the lost-RST everywhere look for $\mathrm{C}$ found-NEG-PEF

I have lost my black pen, for which I have looked all over but still haven't found. 
Tenses, Aspects, and Categories of Evidentiality and Egocentricity in Spoken Lhasa Tibetan

Sentences with "song" and "byung" usually have verbs that are of the opposite direction, i.e., actions moving from the center or not to the center, or results not unexpected or disliked by the speaker. Such verbs include "forget", "fear", "lose", "mistake", etc.

(68) pha-ma-s nga-r rlung-langs-song.

(69) nga-'i lcags-smyug de brlag-song.

Parent-AG I-OBJ angry-PEF

My parents are angry with me.

I-GEN pen that lose-PEF

I've lost my pen.

As we can see, the difference between "song" and "byung" relates closely with the underlying egocentric view of the speaker. Regardless of the pronoun used or the volitionality of the verb, the speaker will use "byung" for egocentric or self-beneficial expressions, but "song" for non-egocentric or non-beneficial expressions. As a result, volitional verbs can be used as non-subjective non-volitional verbs. For instance, sentence (70) indicates the speaker's nonvolitionality of having drunk a lot of alcohol by using the formal marker "song".

(70) a tsi de-ring nga-s chang mang-po zhe-po cig 'thung-song.

alas today I-AG liquor much very drink-PEF

Alas, I have drunk too much liquor today. (now I'm going to get drunk.)

The volitionality of the speaker is usually of prime importance. For instance, sentence (71) seems to be an action towards the self-referent speaker and therefore should have used "byung". But the speaker's intention is revealed through the use of "song" that "I" doesn't want to be recognized because of his certain personal interests. Similarly, "she" in (72) is not the central concern of the speaker, while the speaker still hopes that "she" would be recognized.

(71) kho-s nga ngo-shes-song.

He-AG I recognize-PEF

He has recognized me.

(72) rang kas-mo ngo-shes-byung-ngas. Mo-ni grong-pa-'i w wang-A-yi' i-gyi bu-mo red.

You she recognize-PEF-M.W she-PAP neighbor-GEN Wang aunt-GEN daughter is

Have you recognized her? She's the daughter of Aunty Wang the next door.

Why is there the notion of the speaker's Ego? So far we believe that this notion has something to do with empirical knowledge about the world, the self including of our body, our behaviors and our thoughts. The main body versus object reflects what philosophers thought, knew. Consequently, man as the starting point of cognition enters a relationship with his surroundings in which he is the center of the relationship, i.e., the Ego. Though this cognition will gradually be improved as his relations with the physical world and the society, we can still observe this from a baby's psychological processes. Such an egocentric viewpoint is deeply rooted in the knowledge system of man, and is revealed in certain languages. This is reflected in the self-direction we discussed earlier, and in features such 


\section{Jiang Di Yue Ming}

as gaining or loosing according to the egocentric criteria influenced by the speaker's feelings or determination.

Why not use the "self-person volitional verb" pattern for the perfect aspect? This may have something to do with the social backgrounds of discursive construction. Since the realization of any discursive purpose depends on other people's reaction or attitude, direct expression of egoism (identity, interests) by any individual is restricted. Consequently, idiomatic expressions are developed that are apparently non-egocentric but actually ego-directed (as the other-referent sentences or self-referent non-volitional sentences in Tibetan). Such pragmatic or modality expressions may even be grammaticalized in time.

\section{Resultative}

The Resultative aspect bears the syntactic meaning that the occurrence of an action or the completion of an event has resulted in certain consequence. It has the formal marker "yod" or negative markers "med", "shag/mi 'dug", "yo'o red/yo'o ma red". Both Jin Peng (1983:54) and Denwood (1999:158) consider these to be formal markers of the Perfective. There are still quite a couple of disputes on whether Tibetan has the Perfective aspect. For instance, Jin Peng holds that besides the markers mentioned above, "song" and "byung" are also formal markers of the Perspective. What's the difference between these markers? The word "tshar" in Tibetan used after verbs does indicate the perfective aspect, but it is syntactically a complement.

(73) nga-tshos gzigs-skor-gnang-yas-kyi re'u-mig cig bzos-yod.

We-AG visit-NOM-GEN agenda one make up-RST

We've made up a timetable for the visit.

(74) kha-sa gzugs-po bde-po-ma-byung tsang kha-lag ga-ga'i bzas med.

Yesterday body be well-NEG-PEF consequently meal any eat-NEG-RST

He ate nothing yesterday because he didn't feel well.

(75) kha-sa kyed-rang-gis lan-bskur-gnang-pa de nga-s rbad-de brjed-shag.

Yesterday you-AG send a message-NOM the I-AG completely forget-RST

I've forgotten your messsage completely.

(76) kho-s las-ka yag-pa gcig byed-myong-yo'o-ma-red.

He-AG thing good one do-STC-NEG-RST

He has never done anything good.

The syntactic distribution patterns of the three markers of Resultative are fairly distinct. This may be due to the continued existence of a consequence, which helps people not to get confused. If an event is the narrator's personal experience, the ending is "yod", which may be taken as the archetype; if the event is seen-by-sight of the narrator but not of his personal experience, then " $\mathrm{dug} / \mathrm{shag}$ " is used; if it is a personally experienced 
Tenses, Aspects, and Categories of Evidentiality and Egocentricity in Spoken Lhasa Tibetan

non-volitional action, "'dug" may be used; and if the narrator is merely quoting hearsay or making experiential inference on an event he's not temporally/spatially present at, then "yo'o red" is used.

(77) nga da-dung lag-nags-sprod-yas ca-lag chung-chung de-' dras kha-shas-cig nyo dgos-yod.

I also deliver gift-NOM thing small such some buy need-RST.EG

And I need to buy some small gifts.

(78) kho khal-sa dgong-dga mgyogs-po ra-bzi bkog-btung 'dug.

He yesterday evening nearly drunk drink-RST.SF

He almost got drunk last night.

(79) nga lde-mig khyer-mi-' dug.

I key take-NEG-RST.NI

I don't carry the key with me.

(80) zla-nyin da-tshod rnam-grol lha-sa-r bsdad-yo'o-red.

Last year then rnam-grol Lhasa-LOC stay-RST.JD

Rnam-grol was in Lhasa this time last year.

The Resultative aspect may also be used even if the event is yet to happen, as in (77). Volitional verbs used in non-self-conscious situations may be regarded as non-volitional actions, or as results of non-volitional actions (Sun, 1993), as in (79). Except for the cases in need of speculation,"yo'o red" may also be used in circumstances long before or circumstances not present, as in (80).

With a color of resultative consequences to an event, markers for the Resultative aspect are usually used in sentences indicating the existence of an event or the consequence(s) of an action. For instance, sentences with typical verbs of result, verbs with resultative complement, or auxiliary verbs with a static tendency.

(81) rang-gi stod-thung de-'i tshod-gzhi rbad-de zhud-shag.

You-GEN dress that-GEN color completely fade-RST

The color of your dress completely faded.

(82) mo-s skad-brgyab-cas skad 'bad-ta 'gag 'dug.

She-AG shout voice completely hoarse-RST

She cried herself hoarse.

\section{Contextual aspect}

Although it is not possible for anyone to "witness" any event not yet happened, nor possible for a past event to be repeated, people are none the less able to make their prediction or estimation about such events. If such speculation is based on reliable experiences, then it is reasonable to make a firm judgment on the outcome of the event. Just as if they have "personally experienced or witnessed" the occurrence of an event. The 


\section{Jiang Di Yue Ming}

syntactic meaning of a predicative verb indicates future result of an event, estimated outcomes of a completed event, or the speaker's certainty to such a result. So we call it the "Contextual aspect".

(83) khong-gis skad-cha de shod-pa-mi-'dug.

He-AG words that speak-NEG-RST

He (definitely) wouldn't have said that.

(84) rgan-wang-lags-kyis nga dang khyed-rang-gnyis mgyogs-po shog gsung-gis. lam-sang

teacher Wang-AG I C both of you quickly go tell-DUR immediately

phyin Na-ma-gtogs rgan-wang-lags las-khungs-la bsgus-bzhugs-pa-yod.

go Otherwise teacher Wang office-LOC wait for-CON

Teacher Wang asked you two and me to see him as soon as possible. Let's go immediately, or (I'm sure that) Mr. Wang will be waiting for us in his office.

The formal ending for Tibetan verbs in Contextual aspect is "pa yod/pa 'dug". Denwood (1999:153) regards "pa yod/pa 'dug" as formal markers for the future tense,despite the fact that some sentences are inferences on the result of past events, as in (83). Zhou Jiwen (2003:134) regarded them as expressions of an experientially based speculation.

Having associated this marker with certain time structure and empirical knowledge of the speaker, we regard the combination as the "contextual aspect" so as to emphasize the empirical inference of the outcome of an event.

(85) yul-yar-klung-ni gna'-bo-'i bod-rgyal mang-po de-' dras-kyi bzhugs-gnas yin tsang

地区 yar-klung-PAP times-GEN 藏王 many such-GEN residence consequently

bod-kyi rig gnas dang, Lo-rgyus, sgyu-rtsal-sogs-kyi chu-rgyud gangs-ri zhig red,

Tibet-GEN people history art-GEN riverhead snowberg one is

ces bshad chog-pa-'dug-ga.

and others say can-CON-M.W

Yar-klung is the resident place for many Tibetan kings, and (undoubtedly, it) can be regarded as the riverhead and snowberg of (Tibetan) history and arts.

(86) nga-tsho-'i khang-pa da-lta'i che-chung da-ga-rang 'grigs-pa-' dug.

We-GEN house now-GEN size right suitable-CON

The size of our present house is just right.

The difference between the Contextual and Resultative aspects is that the Resultative aspect is mainly a narration about the result of the event happened, while the Contextual aspect is an inference about the result of a future event. The Contextual differentiates itself from Prospective aspect in that the Prospective Aspect emphasizes the temporal relationship between events, while the Contextual aspect focuses on the outcome of the event. Let's compare (87) and (88) .

(87) rang-gi grogs-po chu-tshod ga-tshod-thog me-'khor-bab-la slebs-kyi-red. 
Tenses, Aspects, and Categories of Evidentiality and Egocentricity in Spoken Lhasa Tibetan

You-GEN schoolmate time how much railway station-ALA arrive at-PRO

When will your schoolmate arrive at the railway station?

(88) nga-gnyis chu-tshod ga-tshod-thog slebs thub-pa-'dug.

We two time how much arrive can-CON

(You are sure ) in how long we can arrive?

Now that the Contextual aspect is an inference about a future event or an event already happened, it can only be used with the non-firsthand-experienced narrative mode. The experience can be used as direct evidence, however, since it has a high degree of certainty. Hence, this aspect usually employs the "pa 'dug" marker. Only sentences with a self-referent take "pa yod" among our examples.

\section{Coda}

Aspectual markers in Lhasa Tibetan are a complicated issue related with many syntactic categories. Particularly since egocentricity and evidentiality as pragmatic-semantic notions have been grammaticalized, they form a complicated multivariant expression system with other categories such as personal pronouns, reference, volitionality, mood, and so on. Apart from those discussed above, in Lhasa Tibetan there are a couple of other syntactic markers that may be combined for the expression of more complicated mood and modality

We have composed a table of syntactic categories such as verbal aspects, evidentiality, egocentricity and others and their formal markers, so that the reader may have a clearer overall picture on these categories. This table is attached to the end of the paper as Appendix II.

\section{Corpus data used}

The spoken Lhasa Tibetan corpus (conducted by the author); "Lha-sa'i kha-skad klog-deb" (A book of oral Lhasa), "Xiao-lin chun-hua" (humorous stories as flowers in spring), "Xiao-lin chun-lei" (humorous stories as thunders in spring), "La-sa kou-yu hui-hua shou-ce" (A handbook of conversation in Lhasa Tibetan),"Qin-xuan shang de hun" (Spirit of strings),and "Si-qu and the father of her three children".

\section{References}

Bell, A. C. 1905. Manual of Colloquial Tibetan. [M] Kathmandu Nepal: Ratna pustak Bhandar (Reprinted 1978).

Chen Ping. 1988. On the ternary structure of time system in contemporary Chinese. [J] Zhongguo Yuwen (Chinese Language). No.6.

Chen Zepin. 1996. Aspect and subjective aspect of verbs in Foochow dialect.[A] In Zhang Shuangqing (ed.): Dongci de Ti (Verb Aspects). [C] Hong Kong: Institute of Chinese cultural studies, Chinese University of Hong Kong.

Dai Qingxia. 2002. Verbal "aspect" and "subjective aspect" in Jingpo Language. [A] In Dai Qingxia (editor-in-chief): Essays in China's Minority Language Studies, Vol. II. [C] Beijing: Nationalities Press.

Dai Yaojing. 1997. Xiandai Hanyu de Shijian Xitiong Yanjiu (A Systemic Study on Time System in Contemporary Chinese). [M] Hangzhou: Zhejiang Education Press.

DeLancey, S. 1986. Evidentiality and Volitionality in Tibetan. [A] In Chafe and Nichols ed, Evidentiality: the linguistic coding of Epistemology. [C] Norwood, New Jersey: Ablex Publishing Corporation. 


\section{Jiang Di Yue Ming}

Deng Shouxin. 1986. Time structure of Chinese verbs. [A] In Anthology of 1st International Chinese Teaching Symposium. [C] Beijing: Publishing House of Beijing Language College.

Denwood, P. 1999. Tibetan. [M] Amsterdam: John Benjamins.

Fu Ailan. 2002. Verbal Aspects in Pumi Language. [A] In Dai Qingxia (editor-in-chief): Essays in China's Minority Language Studies. Vol. II. [C] Beijing: People's Press.

Garrett, E. J. 2001. Evidentiality and Assertion in Tibetan. PH.D.Dissertation. [D] University Of California, Los Angeles.

Goldstein, M. C. 1978. Tibetan-English Dictionary of Modern Tibetan. [Z] New Delhi: Rakesh Press.

Gu Yang. 1999. Verbal Aspects and Modalities. [A] In Xu Liejiong ( editor in chief): Gongxin yu Gexing: Hanyu Yuyanxue Zhong de Zhengyi (Universals and particularities: disputes in linguistic Studies On Chinese). [C] Beijing: Beijing Language and Culture University Press.

Guo Rui. 1993. Procedure Structure of Verbs in Chinese. [J] Zhongguo Yuwen (Chinese Language). No.6.

Hannah, H. B. 1912. A Grammar of the Tibetan Language. [M] Delhi: Motilal Banarsidass Publisher (reprint, 1996).

$\mathrm{Hu}$ Tan. 2002. Catgories of verbal aspect in Tibetan. [A] In Dai Qingxia (editor-in-chief): Essays in Chinese Minority Language Studies, Vol. II. [C] Beijing: Nationalities Press.

Jiang Di. 1999. Formal Markers of the Present Tense and their functions in Lhasa Tibetan. [J] Minority Languages of China. No.5.

Jiang Di. 2004. Syntactic Rules, Word Classes and Chunk Tags of Modern Tibetan for Language Processing. [A] In Jiang Di, Kong Jiangping (editors in chief): Advances on the Minority Languages Processing. [C] Beijing: Social Sciences Academic Press.

Jiang Di. 2006. Approaches on Methods of the Latin Transliteration in Tibetan. [J] Minority Languages of China. No.1.

Jin Peng (editor in chief). 1983. Zangyu Jianzhi (A Brief Introduction to Tibetan Language). [M] Beijing: Nationalities Press.

Liu Xunning. 1989. The syntactic meaning of “了(le)" in Modern Chinese. [J] Zhongguo Yuwen (Chinese Language). No.5.

Mead, G. H. 1999. "Mind, Self, Society" (Chinese translation). [M] Beijing: Huaxia Press.

Mei Guang. 1996. A study on sentential endings in Dulong Language. [J] Language Study. No.1.

Mu Shihua. 2002. On aspectual categories of Naxi verbs. [A] In Dai Qingxia (editor-in-chief): Essays in China's Minority Language Studies. Vol. II. [C] Beijing: People's Press.

Qu Aitang \& Tan Kerang. 1983. Ali Tibetan. [M] Beijing: Chinese Social Sciences Press.

Qu Aitang. 2000. Tibetan syntactic system. [A] In Qu Aitang \& Jin Song: Theories and Methodologies in Sino-Tibetan Languagues Studies. [C] Beijing: Chinese Tibetan Studies Press.

Randy, J. L. 2003. Evidentiality in Qiang. [A] In A. Y. Aikhenvald \& R. M. W. Dixon ed, Studies in Evidentiality. [C] Amsterdam \& Philadelphia: John Benjamins.

Shefts, C. B. \& Kun Chang. 1981. Perfective and Imperfective in Spoken Tibetan. [J] Bulletin of the Institute of History and Philology. Vol.52. Academica Sinica.

Shi Yuzhi. 1992. On markers of verb aspect in Modern Chinese. [J] Zhongguo Shehui Kexue (Chinese social sciences). Vol.6.

Sun, Jackson T. S.. 1993. Evidentials in Amdo Tibetan. [J] The bulletin of the institute of history and philology. Vol. 63. No.4. Academica Sinica.

Van Valin, Robert D., Jr. \& Randy J. L. 1997. Syntax: Structure, Meaning and Function. [M] London: Cambridge University Press.

Wylie, T. 1959. A standard system of Tibetan transcription. [J] Harvard Journal of Asiatic Studies Vol.22.

Yang Jiangling. 2003. Verbal aspect in Dulong Language. [A] In Dai Qingxia (editor-in-chief): Essays in Chinese Minority Language Studies, Vol. II. [C] Beijing: Nationalities Press.

Zhou Jiwen \& Xie Houfang. 2003. Zang-yu La-sa-hua Yu-fa (A Grammar book of Lhasa Tibetan). [M] Beijing: Nationalities Press.

Zuo Simin. 1999. Studies on Verbal Aspects in Modern Chinese and the Typological Significance of Aspect Investigation. [J] Yuwen Yanjiu (Studies of the Chinese Language). No.1. 
Tenses, Aspects, and Categories of Evidentiality and Egocentricity in Spoken Lhasa Tibetan

\section{Appendix I: Table of verbal aspect and tense markers in Lhasa Tibetan}

(For Hoshi, Michio's classification, see Hu Tan (2002). For classifications by others, see their corresponding works in the references.)

\begin{tabular}{|c|c|c|c|c|c|}
\hline No. & Aspect marker & Jin Peng & Qu Aitang & Zhou Jiwen & Hoshi, Michio \\
\hline 1 & gi yin /gi red & $\begin{array}{l}\text { the prospective } \\
\text { tense }\end{array}$ & $\begin{array}{l}\text { prospective } \\
\text { aspect }\end{array}$ & future tense & $\begin{array}{l}\text { imperfective- } \\
\text { non-durative }\end{array}$ \\
\hline 2 & $\begin{array}{l}\text { mkhan yin / mkhan } \\
\text { red }\end{array}$ & & & future tense & \\
\hline 3 & $\begin{array}{l}\text { grabs yod / grabs } \\
\text { 'dug/grabs yo'o red }\end{array}$ & imminent tense & $\begin{array}{l}\text { imminent } \\
\text { aspect }\end{array}$ & future tense & \\
\hline 4 & rgyu yin / rgyu red & $\begin{array}{l}\text { not-happened- } \\
\text { about-to-happen } \\
\text { tense }\end{array}$ & preparative & future tense & \\
\hline 5 & $\begin{array}{l}\text { gi yod / gi 'dug /gi } \\
\text { yo'o red }\end{array}$ & ongoing tense & $\begin{array}{l}\text { present } \\
\text { aspect }\end{array}$ & present tense & $\begin{array}{l}\text { imperfective-d } \\
\text { urative }\end{array}$ \\
\hline 6 & grabs yin / grabs red & $\begin{array}{l}\text { merely-past } \\
\text { tense }\end{array}$ & $\begin{array}{l}\text { merely past } \\
\text { aspect }\end{array}$ & procedure past & \\
\hline 7 & pa yin / pa red & finished tense & past aspect & procedure past & $\begin{array}{l}\text { perfective-non- } \\
\text { durative }\end{array}$ \\
\hline 8 & pa yod / pa 'dug & & & inference mood & \\
\hline 9 & $\begin{array}{l}\text { yo'o / 'dug } \\
\text { (shag)/yo'o red }\end{array}$ & perfect aspect & resultative & resultative past & $\begin{array}{l}\text { perfective- } \\
\text { durative }\end{array}$ \\
\hline 10 & song / byung & perfect aspect & $\begin{array}{l}\text { perfect } \\
\text { aspect }\end{array}$ & procedure past & $\begin{array}{l}\text { perfective -non } \\
\text {-durative }\end{array}$ \\
\hline 11 & mus yin / mus red & & & & \\
\hline 12 & red 'dug /red shag & & & & \\
\hline 13 & chog yin / chog red & & & & \\
\hline 14 & yag yin / yag red & & & & \\
\hline 15 & yong & & & future outcome & \\
\hline 16 & rgyu byung & & & objective past & \\
\hline
\end{tabular}




\section{Jiang Di Yue Ming}

(Continued)

\begin{tabular}{|l|l|l|l|}
\hline No. & \multicolumn{1}{|c|}{ Aspect marker } & \multicolumn{1}{|c|}{ P. Denwood } & \multicolumn{1}{|c|}{ This essay } \\
\hline 1 & gi yin /gi red & future tense & prospective aspect \\
\hline 2 & mkhan yin / mkhan red & prospective aspect -premeditated aspect & prospective aspect \\
\hline 3 & grabs yod / grabs & prospective aspect- imminent aspect & imminent aspect \\
\hline 4 & rgyu yin / rgyu red & prospective aspect - gerundive aspect & premediated aspect \\
\hline 5 & gi yod / gi 'dug /gi yo'o red & $\begin{array}{l}\text { present tense (can be used as progressive } \\
\text { aspect) }\end{array}$ & durative \\
\hline 6 & grabs yin / grabs red & perfect aspect-newly perfect aspect & merely past aspect \\
\hline 7 & pa yin / pa red & past (can be used as customary aspect) & realis \\
\hline 8 & pa yod / pa 'dug & $\begin{array}{l}\text { future tense (can be used as customary } \\
\text { aspect) }\end{array}$ & contextual aspect \\
\hline 9 & yo'o / 'dug (shag)/yo'o red & perfect aspect- simple perfect aspect & resultative \\
\hline 10 & song / byung & past tense & perfect aspect \\
\hline 11 & mus yin / mus red & progressive aspect & \\
\hline 12 & red 'dug /red shag & perfect aspect- with an existential verb & \\
\hline 13 & chog yin / chog red & prospective aspect-preparative aspect & \\
\hline 14 & yag yin / yag red & prospective aspect & \\
\hline 15 & yong & rgyu byung & \\
\hline 16 & & \\
\hline
\end{tabular}


Tenses, Aspects, and Categories of Evidentiality and Egocentricity in Spoken Lhasa Tibetan

Appendix II: Distribution of verb aspect markers and evidential markers in Lhasa Tibetan

\begin{tabular}{|c|c|c|c|c|c|c|}
\hline \multirow{2}{*}{\multicolumn{2}{|c|}{$\begin{array}{l}\text { Narrative Viewpoint } \\
\text { Evidentiality Type }\end{array}$}} & Ego & \multicolumn{4}{|c|}{ Non-ego } \\
\hline & & Meta-evidence & \multicolumn{3}{|c|}{ Direct Evidence } & $\begin{array}{l}\text { Indirect } \\
\text { Evidence }\end{array}$ \\
\hline \multirow{2}{*}{\multicolumn{2}{|c|}{$\begin{array}{l}\text { Experiential Knowledge } \\
\text { (Explanation) }\end{array}$}} & $\begin{array}{l}\text { Self-knowledge } \\
\text { (personal } \\
\text { experience) }\end{array}$ & \multicolumn{2}{|c|}{$\begin{array}{l}\text { Knowing-by- } \\
\text { Sight (personal } \\
\text { witness) }\end{array}$} & $\begin{array}{l}\text { Knowing-by- } \\
\text { newly-found- } \\
\text { information } \\
\text { (discover) }\end{array}$ & $\begin{array}{l}\text { Knowing-by- } \\
\text { inferential } \\
\text { (speculation) }\end{array}$ \\
\hline & & I did... & \multicolumn{2}{|c|}{ (I saw) he did... } & $\begin{array}{l}\text { (I discover } \\
\text { that I) was... }\end{array}$ & $\begin{array}{l}\text { (I guess) he } \\
\text { did.../it was... }\end{array}$ \\
\hline \multicolumn{2}{|c|}{ Parameter Relationship } & $\begin{array}{l}\text { Self-person, } \\
\text { [+volition] }\end{array}$ & \multicolumn{2}{|c|}{$\begin{array}{l}\text { Other-person, } \\
\text { [ } \pm \text { volition }]\end{array}$} & $\begin{array}{l}\text { Self-person, } \\
\text { [-volition] }\end{array}$ & $\begin{array}{l}\text { Self-person, } \\
\text { [-volition] / } \\
\text { other-person, } \\
\text { [ } \pm \text { volition }]\end{array}$ \\
\hline \multicolumn{2}{|c|}{ Prospective Aspect } & gi yin & & & & gi red \\
\hline \multicolumn{2}{|c|}{ Imminent Aspect } & grabs yod & \multicolumn{3}{|c|}{ grabs 'dug } & grabs yo'o red \\
\hline \multicolumn{2}{|c|}{ Premediated Aspect } & rgyu yin & \multicolumn{3}{|c|}{$\begin{array}{l}\text { (rgyu } \\
\text { red) }\end{array}$} & rgyu red \\
\hline \multicolumn{2}{|l|}{ Realis } & pa yin & & & & pa red \\
\hline \multicolumn{2}{|l|}{ Durative } & gi yod & \multicolumn{3}{|c|}{ gi 'dug (/gis) } & gi yo'o red \\
\hline \multicolumn{2}{|c|}{ Merely Past Aspect } & grabs yin & \multicolumn{3}{|c|}{$\begin{array}{c}\text { grabs } \\
\text { red }\end{array}$} & \\
\hline \multicolumn{2}{|c|}{ Resultative } & yod & \multicolumn{3}{|c|}{ 'dug (/shag) } & yo'o red \\
\hline \multicolumn{2}{|c|}{ Contextual Aspect } & pa yod & \multicolumn{3}{|c|}{ pa 'dug } & \\
\hline \multirow{3}{*}{$\begin{array}{l}\text { Perfect } \\
\text { Aspect }\end{array}$} & & & + & & - & \\
\hline & Extroversion & & song & song & song & \\
\hline & Introversion & & byung & & byung & \\
\hline
\end{tabular}

